\title{
El título valor y su incidencia como instrumento de comercio en la bolsa de valores
}

\author{
The security and its incidence as a trading instrument in the stock market \\ O título e sua incidência como instrumento de negociação na bolsa de valores
}

Artículo recibido en octubre 2020

Arbitraje en noviembre 2020

Aceptación en diciembre 2020

Publicación en enero 2021
Kristian Guillermo Nieto Hernández

hernanhernndez@yahoo.com

https://orcid.org/0000-0002-9552-0898

Universidad Andina Simón Bolívar, Quito-Ecuador
RESUMEN

ABSTRACT
La investigación tuvo como objetivo principal determinar el título de valor y su incidencia como instrumento de comercio, en la bolsa de valores de Quito. La metodología usada fue de tipo descriptivo con un diseño documental de campo, bajo un enfoque cualitativo y cuantitativo, con un método, inductivo, deductivo, histórico, lógico, la técnica e instrumento utilizado fue la entrevista y la encuesta (cuestionario) la población y la muestra estuvo conformada por 1 abogado del departamento jurídico bolsa de valores de Quito y 10 abogados expertos en derecho bursátil. Se obtuvo como resultado que es necesario una reforma en la Ley de Mercado de Valores, para emplear a los títulos valores como instrumentos de comercio. Por lo que se concluyó que el mercado de valores es importante para cualquier país porque procura el desarrollo de actividades financieras que fortalecen su economía.

Palabras clave: Bolsa de valor; casa de valores; ley de mercado de valores; título de valor, mercado de valores

The main objective of the research was to determine the value title and its incidence as a trading instrument in the Quito stock exchange. The methodology used was descriptive with a field documentary design, under a qualitative and quantitative approach, with an inductive, deductive, historical, logical method, the technique and instrument used was the interview and the survey (questionnaire) the population and the sample consisted of 1 lawyer of the legal department of the Quito stock exchange and 10 lawyers experts in securities law. The result was that it is necessary to reform the Securities Market Law in order to use securities as trading instruments. Therefore, it was concluded that the stock market is important for any country because it seeks the development of financial activities that strengthen its economy.

Key words: Stock exchange; securities house; securities market law; securities, securities market

RESUMO

O principal objetivo da pesquisa era determinar o título de valor e sua incidência como instrumento de negociação na bolsa de Quito. A metodologia utilizada foi descritiva com um projeto documental de campo, sob uma abordagem qualitativa e quantitativa, com um método indutivo, dedutivo, histórico, lógico, a técnica e o instrumento utilizado foi a entrevista e a pesquisa (questionário). A população e a amostra consistiu de 1 advogado do departamento jurídico da bolsa de Quito e 10 advogados especialistas em direito do mercado de ações. O resultado foi a necessidade de reformar a Lei do Mercado de Valores Mobiliários a fim de utilizar os valores mobiliários como instrumentos de negociação. Portanto, concluiu-se que o mercado acionário é importante para qualquer país porque busca o desenvolvimento de atividades financeiras que fortalecem sua economia.

Palavras-chave: Bolsa de valores; casa de títulos; lei do mercado de títulos; títulos, mercado de títulos 


\section{INTRODUCCIÓN}

El mercado de valores o también denominado mercado de capitales. Es un espacio económico donde se reúnen ofertantes y demandantes de valores, y cumple la función de captar recursos financieros a través de la compra y venta de instrumentos financieros, con el objetivo de financiar capital de trabajo de manera directa canalizando los recursos financieros, hacia el desarrollo de actividades productivas, y a costos reducidos.

Para este efecto el mercado de valores utiliza títulos de crédito, denominados títulos valores, que representan una obligación por cumplirse.

Los títulos de valores, son conocidos de diversas maneras, entre ellos el más común es el título de crédito, seguidos de títulos circulatorios, efectos de comercio, documentos negociables, entre otros. No obstante, consisten en una obligación que debe cumplirse en determinado tiempo, y que mientras tanto es susceptible de negociación.

El título de valor en el Ecuador, es un documento por el cual, se pueden establecer relaciones de comercio, que son exigibles de forma inmediata. No obstante del fundamento legal, es decir la Ley de Mercado de Valores no contempla tácitamente, que el título de valor pueda ser utilizado como un instrumento de comercio, lo cual beneficiaría la dinámica de la economía en términos generales.

Sin embargo, en el ámbito privado, los títulos de valores no han logrado consolidar este avance, porque los títulos, al tener un valor autónomo incorporado, son plenamente exigibles, y podrían ser utilizados como circulante en transacciones mercantiles, práctica que representaría una trasformación en la dinámica mercantil, comercial y nacional, hecho que a subes abriría a las personas comunes, la posibilidad de realizar inversiones, adquiriendo títulos de valores, que al final del día les producirán dividendos.

En este sentido, en el artículo 233 de la Ley de Mercado de Valores establece que:

Los valores a que se refiere el artículo 2 de esta Ley, tienen el carácter de títulos valor, en consecuencia, incorporan un derecho literal y autónomo que se ejercita por su portador legitimado según la ley, constituyen títulos ejecutivos para los efectos previstos en el artículo 413 del Código de Procedimiento Civil. Se presume, salvo prueba en contrario, su autenticidad así como la licitud de su causa y la provisión de fondos.

Un aspecto importante que se desprende del artículo 233 de la Ley de Mercado de Valores es que se otorga la calidad de títulos ejecutivos, a los documentos contemplados en el artículo 2. De la misma ley, se puede conceptualizar lo que se entiende por título valor, esta calidad implica que procesalmente se pueda exigir en juicio el cumplimiento de la obligación por 
la vía ejecutiva contemplada tanto en el Código de Procedimiento Civil, como en el Código Orgánico General de Procesos, facultad legal que permite proceder sumariamente al embargo o secuestro de los bienes del deudor moroso a fin de garantizar la recuperación del capital constante en dichos documentos, así como también los intereses legales y costas procesales que se deriven de dichos tramites.

Por todo lo expuesto, se puede decir, que el título de valor en el País Ecuador, es un documento de fácil cobro, pues la ley civil presta todas las garantías para poder ejecutarlo, motivo por el cual se pueden establecer relaciones de comercio. No obstante, la Ley de Mercado de Valores no faculta que el titulo valor pueda ser utilizado como un instrumento de comercio, práctica que de ser ejecutada, en las transacciones mercantiles y comerciales, potenciaría la actividad economía, generando beneficios en la economía nacional.

La utilización del título valor como instrumento de comercio no se practica en Ecuador, porque la Ley de Mercado de Valores no incentiva a los actores comerciales y mercantiles a desarrollar esta práctica. A pesar de esto la administración pública ya ha utilizado al título de valor como medio de pago, al emitir estos documentos como pago por compensación a jubilaciones, con el cambio del Reglamento de la Ley Orgánica de Servicio Público (LOSEP).

Sin embargo, en el sector privado no se ha producido este cambio, que podría significar mejoras en la economía nacional, así como la posibilidad de que las personas comunes inviertan su dinero en títulos de valores que les produzcan dividendos.

Con las consideraciones expuestas, se evidencia las consecuencias por no utilizar los Títulos de Valores en las transacciones comerciarles diarias, o al menos en las que fuera posible hacerlo, generando de esta forma una cultura bursátil pobre. Por lo tanto, el estudio presenta como objetivo general determinar el título de valor y su incidencia como instrumento de comercio, en la Bolsa de Valores de Quito. Presentándose así, la posibilidad, de desarrollar en el país una cultura bursátil en la que se utilice abiertamente a los títulos valores como instrumento de comercio, y poder comercializarlos de manera inmediata.

\section{Título valor}

La palabra título valor proviene etimológicamente del latín, de las palabras "titulusi" título, y de "valoris" valor. Estos títulos son representativos de un derecho económico, y pueden ser negociados en un mercado de valores, y a subes siempre pertenecerán a un legítimo propietario.

Cevallos (2013), al respecto dice que los títulos de valores abarcan el Mercado de Valores, en sus segmentos bursátil, extrabursátil y bolsa de valores, con la finalidad de comerciar documentos que poseen un valor y que son susceptibles de compra y venta por parte de los accionistas. (p. 510). 
Andrade (2014), dice sobre el tema:

Resulta preferible utilizar una terminología que se ha generalizado en América Latina, como consecuencia de los Proyectos de la Ley Uniforme de Títulos Valores para Centro América y América Latina, de las sugerencias del Parlamento Latinoamericano y que ha sido adoptada por tres países de la subregión, y que en los países de habla castellana cuenta con la general aceptación por el entusiasta impulso que le ha dado su introductor, don Joaquín Garrigues, usando el nombre de título de valor. (p. 34).

Ramírez (2004) a su vez, indica:

Estimo que la denominación correcta y la que debemos mantener cómo genérica es la de "título valor" que abarca a los documentos de diversas y diferentes características específicas, no todo título de valor es un título de crédito; en cambio todo título de crédito es un título valor. La acción de una compañía de capital, que es un título valor, no es necesariamente un título de crédito, no atribuye un solo derecho de crédito a su titular (p. 23).

Y Lorenzo (1924) dice: "...que en lo jurídico, el crédito indica una promesa de pago que resulta de un contrato en el que una parte se compromete a cumplir una obligación al vencerse ésta." (p. 304).

De esta manera se puede decir, que el título de crédito (títulos abstractos, títulos cambiarios o papeles de comercio) es una denominación específica y exclusiva que se otorga a aquellos documentos que dan un derecho a crédito o que obligan y dan derecho a una prestación de dinero que tienen características particulares que los diferencian de los demás títulos valor.

\section{Características de los títulos de valores}

Las principales características de los títulos valores son las que se detallan a continuación:

- Son Necesarios. En el sentido que para ejercer el derecho consignado en el título, el legítimo tenedor debe disponer del mismo. En el ejercicio profesional se debe tener muy presente que si desea reclamar el pago de un título valor, debe disponer del mismo, en forma legítima. No puede reclamar el pago de una letra de cambio, por ejemplo, sino dispone del título.

- Son Legítimos. Se restaría velocidad, seguridad y confianza si al título valor tendría que someterse a procedimientos adicionales, para que adquiera total legitimidad. Por eso, la solución doctrinaria y legal es mucho más práctica: se presume legítimo al título. De entrada. (Esto, sin perjuicio de ciertos requisitos que impone la Ley, para justificar la legítima tenencia), como es el reconocimiento de firmas del endosante. 
- Son Literales. Si el título incorpora (representa, simboliza), el derecho y la obligación cautelar, lo menos que hay que exigirle al título es que esté expresada literalmente la obligación, no tendría aceptación si la obligación no es precisa.

- Son Solemnes. Los títulos valor no pueden ser emitidos, o circular de una manera anárquica y caprichosa, no pueden crearse de manera desordenada y desprolija, y tampoco podrán circular de la misma manera. Deben sujetarse a requisitos legales, o, por lo menos, a formalismos aplicados por costumbre mercantil.

\section{Clases de título valor}

Los títulos valores tienen 3 clasificaciones principales:

Rentabilidad. Cuando se estudia al título valor en función de su rentabilidad, debe indicarse que está puede ser fija o variable, en función de lo que las partes hayan acordado.

La rentabilidad fija consiste en que, los títulos valores emitidos obtendrán un dividendo previamente establecido, a satisfacción del emisor y del beneficiario, sin que ninguna de las partes pueda cambiar dichos términos. Según el artículo 30 de la Ley de Mercado de Valores se define: "Los Valores de renta fija son aquellos cuyo rendimiento no depende de los resultados de la compañía emisora, sino que está predeterminado en el momento de la emisión y es aceptado por las parte." (s/p).

En el caso de la rentabilidad variable, el título de valor no posee una utilidad previamente establecida, sino que depende del desenvolvimiento del negocio del emisor para realizar determinado pago de utilidades. El artículo 32 de la Ley de Mercado de Valores dice que: "De los valores de renta variable.- Valores de renta variable son el conjunto de los activos financieros que no tienen un vencimiento fijo y cuyo rendimiento, en forma de dividendos o capital, variará según el desenvolvimiento del emisor." (s/p).

Según el sector. Los títulos valores pueden estar supeditados a la entidad que los emita, pudiendo ser está privada o pública.

Sector público. cuando se habla de títulos valores emitidos en el sector público, se hace referencia a aquellos que son emitidos por el estado, a través de cualquiera de sus instituciones, posiblemente el título valor emitido en el sector público y que posee más connotación, son los bonos del estado, en este caso se sujeta a una rentabilidad variable. Según la Ley del Mercado de Valores en el artículo 37 indica:

De las inversiones del sector público a través de las bolsas de valores. Las inversiones y Compra-venta de activos financieros que realicen directa o indirectamente las entidades y organismos del sector público, que excedan mensualmente del valor de dos mil seiscientos veintiocho 90/100 $(2.628,90)$ 
dólares de los Estados Unidos de América, podrán realizarse a través de los sistemas de negociación bursátiles interconectados entre las bolsas de valores establecidas en el país. (s/p).

Mientras que el sector privado, los títulos valores que se generan en ese sector, son los de uso más común, ya que expresan de mejor manera al título valor y su influencia en el mercado. Se trata de títulos valores emitidos por particulares, en su afán por obtener inversión y acrecentar su negocio, se trata de compañías limitadas, que encuentran en el título valor un medio perfecto para el financiamiento de sus negocios. Según la Ley del Mercado de Valores, artículo 39: "el mercado secundario, comprende las operaciones o negociaciones que se realizan con posterioridad a la primera colocación; por lo tanto, los recursos provenientes de aquellas, los reciben sus vendedores.

Según la responsabilidad que genera. Dentro del caso de la responsabilidad que genera se entiende que el título valor puede ser de responsabilidad limitada o ilimitada.

Los títulos de valores de responsabilidad limitada, son los que solamente responden por el monto de sus aportaciones individuales Si se utilizare una denominación objetiva será una que no pueda confundirse con una preexistente. Es decir son responsables de cierto porcentaje de las deudas y obligaciones de la misma.Y los títulos de valores de responsabilidad ilimitada, significa que son igualmente responsables por todas las obligaciones contraídas y no se limitan como en el caso anterior. En este caso el individuo, dueño del título valor, será responsable ilimitadamente, es decir independientemente de monto de sus títulos valores, ligaciones contraídas y no se limitan como en el caso anterior.

\section{Mercado de valores}

El mercado de valores también denominado mercado de capitales es un espacio económico donde se reúnen ofertantes y demandantes de valores, cumple la función de captar recursos financieros a través de la compra y venta de instrumentos financieros, con el objetivo de financiar capital de trabajo de manera directa y a costos reducidos.

Según Thompson (2006), el mercado de valores "es aquel mercado en el que se negocian activos financieros de corto plazo, principalmente derivados de las operaciones comerciales o crediticias" (p. 11).

\section{Estructura del mercado de valores}

En Ecuador, las principales instituciones encargadas de regular el mercado de valores son: Consejo Nacional de Valores. Establece la política general del mercado de valores y regula su funcionamiento. 
- La Superintendencia de Compañías y Valores. Institución que ejecuta la política general del mercado de valores y controla a los participantes del mercado.

- Las bolsas de valores. Esta tiene su propia autorregulación, pues pueden dictar sus reglamentos y demás normas internas de aplicación general para todos sus partícipes, así como, ejercer el control de sus miembros e imponer las sanciones dentro del ámbito de su competencia.

\section{Bolsas de valores}

Son mercados de comercio en donde se intercambian títulos valores e instrumentos financieros de variada índole. Es el lugar donde se confrontan ofertas y demandas, que permite una gran concentración de actividades comerciales y la fijación de los precios de manera, probablemente, la más exacta.

En el país Ecuador, las bolsas de valores, son corporaciones civiles sin fines de lucro, autorizadas y controladas por la Superintendencia de Compañías, sujetas a las disposiciones de la Ley de Mercado de Valores y resoluciones expedidas por el Consejo Nacional de Valores.

Su objeto es brindar a sus miembros, las casas de valores, los servicios y mecanismos requeridos para la negociación de valores en condiciones de equidad, transparencia, seguridad y precio justo. Estas operaciones se dan en el marco de un conjunto de normas y reglas uniformes.

\section{Rol de la bolsa de valores en la economía}

Para definir su rol en la economía, se debe partir de la idea de que la bolsa es un mercado, es un subsistema dentro del sistema financiero y está compuesto por un conjunto de instrumentos o activos financieros, instituciones o intermediarios, donde se reúnen compradores y vendedores para intercambiar activos financieros.

En el mercado de valores participarían intermediarios (operadores de valores), quienes están autorizados a realizar operaciones, por encargo de los clientes mediante la compra/venta de títulos de valores (acciones, bonos, pagares), emitidos por empresas inscritas en la bolsa, siendo estos los emisores.

En las bolsas, los jugadores son las empresas y los inversores. Dichas empresas tienen en la bolsa una buena forma de conseguir financiamiento para sus planes a través de la venta de acciones. El inverso desea obtener una rentabilidad de sus excedentes y acude a la bolsa para comprar acciones, u otros productos emitidos por las empresas. El rol de la bolsa de valores consiste en proporcionar a los participantes información veraz, objetiva, completa y permanente de los valores y de las empresas en ella inscritas, así como también supervisar todas sus actividades, según las regulaciones vigentes. 


\section{Casas de valores}

Son compañías anónimas autorizadas y controladas por la Superintendencia de Compañías, miembros de una bolsa de valores, cuyo objeto es la intervención de valores.

Una casa de valores es la compañía anónima autorizada y controlada por la Superintendencia de Compañías para ejercer la intermediación de valores, cuyo objeto social único es la realización de las actividades previstas en la ley.

Una casa de valores y un banco actúan en diferentes mercados. La primera, participa en los mercados de desintermediación financiera, mientras que el segundo, lo hace en el de intermediación financiera.

\section{Fundamentación normativa}

La investigación se apoyo en el marco legislativo de dos leyes en particular, la ley del mercado de valores (Registro Oficial Suplemento 215 de 22-feb- 2006) conjunto a las reformas a la ley orgánica para el fortalecimiento y optimización del sector societario y bursátil (Registro Oficial Suplemento 249 de 20- mayo-2014).

Se crea la Junta de Regulación del Mercado de Valores, como un organismo de derecho público perteneciente a la función ejecutiva, que será la encargada de establecer la política pública del mercado de valores y dictar las normas para el funcionamiento y control de dicho mercado en concordancia con lo establecido en la Constitución y los principios y finalidades establecidos en esta ley.

Además, regula la creación y funcionamiento de las casas de valores, calificadoras de riesgos, bolsas de valores, la sociedad proveedora y administradora del sistema único bursátil, los depósitos de compensación y liquidación de valores, las administradoras de fondos y fideicomisos, así como los servicios que estas presten.

Se establecen los requisitos de estandarización, numeración e identificación de los valores. Regula los procesos para la certificación, inscripción y homologación de los operadores de valores bajo criterios de capacitación, conocimiento, profesionalismo, experiencia, ética y actualización.

En el cuerpo legal se incorporan reglas de participación en los procesos, así como obligaciones de los funcionarios públicos; por tanto, se incorpora una excepción para la bolsa pública de ser accionista de la compañía anónima proveedora y administradora del sistema único bursátil, estableciendo con claridad para este caso que la Junta de Regulación del Mercado de Valores determinará la forma de interconexión del sistema bursátil que utilice la bolsa de valores pública, con el Sistema Único Bursátil que proveerá la Sociedad Proveedora y Administradora del Sistema Único Bursátil para las bolsas de valores privadas. 
Crea una contrapartida central con el objeto de mitigar los riesgos existentes por incumplimiento de las obligaciones en efectivo y de instrumentos financieros derivados que se negocien en el mercado de valores. Esta contrapartida no cubre los mismos riesgos que ya están cubiertos por el fideicomiso de garantía de compensación y liquidación que se crea en esta ley para el efecto; en consecuencia, la entidad de contraparte central garantizará el cumplimiento de las operaciones bursátiles que no se hubieren compensado aún, particularmente aquellas negociaciones sobre futuros y derivados.

En las reformas a la Ley de Mercado de Valores se incluye la posibilidad de emitir valores mixtos de participación en proyectos inmobiliarios, ya que es necesario que el inversionista que vaya a entregar su dinero se vea atraído y respaldado en la posibilidad de que reciba una renta fina preestablecida y una renta variable en función de los resultados del proyecto inmobiliario. Por tanto, en el documento se agregan 2 artículos sin número sobre la titularización de proyectos inmobiliarios y de derechos existentes generadores de flujos futuros o de proyectos susceptibles de generar flujos futuros determinables.

La Superintendencia de Compañías y Valores ejercerá las funciones de vigilancia, auditoría, intervención y control del mercado de valores con el propósito de que las actividades de este mercado se sujeten al ordenamiento jurídico y atiendan al interés general, y podrá autorizar las ofertas públicas de valores y aprobará el contenido del prospecto.

\section{MÉTODO}

El estudio fue desarrollado con una metodología de tipo descriptivo, porque a través de la observación actual de los fenómenos y casos, se procuró la interpretación racional de los mismos. Además, se usó el diseño documental y de campo. El primero, dado a que la investigación fue apoyada en fuentes bibliográfica, hemerográfica y archivística; y el segundo, porque se investigó en el lugar de los hechos, en este caso, el contacto directo con la realidad de la bolsa de valores de Quito, donde se aplicó los instrumentos.

Adicional, el enfoque que se usó durante el desarrollo de la investigación fue el mixto (cualitativo y cuantitativo), cualitativo, porque en primer término se interpretó, analizó la situación de los títulos de valores y su incidencia en calidad de instrumentos de comercio; cuantitativo, porque se aplicó los procesos estadísticos que permitieron verificar el objetivo general del estudio.

A su vez, los métodos usados fueron, inductivo porque se analizó otros factores como por ejemplo la revisión casuística, deductivo ya que, se detalló toda la estructura determinada en la Constitución, analítico-sintético, porque este método hizo posible la comprensión de todo hecho, fenómeno, idea, caso e histórico - lógico, dado a que, se analizó científicamente los hechos, ideas del pasado comparándolo s con hechos actuales. 
En cuanto a la población que conformó el estudio, estuvo constituida por los siguientes involucrados: 1 abogado del departamento jurídico bolsa de valores de Quito y 10 abogados expertos en derecho bursátil. Como la población no es cuantiosa, no existió la necesidad de tomar una muestra, por cuanto la investigación de campo abarcó el universo.

Por último, las técnicas e instrumentos que se usaron para la recolección de datos fueron la entrevista, y la encuesta; la primera se apoyó con un cuestionario, la cual fue aplicado al abogado del departamento jurídico, de la bolsa de valores de Quito, y la segunda, fue aplicado a 10 abogados especialista en derecho bursátil por medio de un cuestionario.

RESULTADOS

Para el procesamiento, análisis y discusión de resultados se utilizaron técnicas estadísticas y lógicas. Para la interpretación de los datos se realizó través de la inducción, el análisis y la síntesis, por lo cual se tomó en cuenta la información recabada. La entrevista aplicado al abogado del departamento jurídico de la bolsa de valores de Quito, estuvo dirigida por un cuestionario, la misma presentó 5 ítems.

Ítems 1. Título de valor, el informante señaló que es un documento revestido de garantías, por cuanto el valor que se expresa es pagadero en una fecha, incluyendo un interés. De esta manera, se afirma, que el abogado, esta informado sobre el tema.

Ítems 2. Instrumento de comercio, el informante indica que los instrumentos son uno que se puede vender y comprar libremente.

Ítems 3. Criterio. Utilizar un título de valor como un instrumento de comercio, el informante comentó que si es posible utilizar un titulo de valor como un instrumento de comercio, aunque en la ley no se exprese puntualmente, como el pago de las jubilaciones con los bonos del estado.

Ítems 4. La Ley de Mercado de Valores otorga un carácter de comercio a los títulos valores, el informante, señala que si cree, que la ley de mercado de valores otorga ese carácter a los títulos de valores, por cuanto cualquiera puede comprarlos y venderlos.

Ítems 5. Reformar la ley de mercado de valores, el informante indica que si cree que los títulos de valores deberían utilizarse diariamente para cualquier transacción, una reforma en este sentido sería importante.

Por otro lado, la encuesta dirigida a 10 abogados en el libre ejercicio expertos en derecho bursátil, el cual se aplicó el cuestionario, se obtuvo como resultado, lo siguiente: 


\section{Ítems 1. Título de valor concepto}

En la Tabla 1, se muestra que de las encuestas realizadas el $100 \%$ de los abogados en el libre ejercicio expertos en derecho bursátil, indican que conocen lo que es un título valor.

Tabla 1. Concepto.

\begin{tabular}{ccc}
\hline ALTERNATIVAS & FRECUENCIA & $\%$ \\
\hline $\mathrm{Si}$ & 10 & 100 \\
No & 0 & 0 \\
TOTAL & $\mathbf{1 0}$ & $\mathbf{1 0 0}$ \\
\hline
\end{tabular}

\section{Ítems 2. Instrumento de comercio}

Seguidamente, en la Tabla 2, se muestra que de las encuestas realizadas el $100 \%$ de los abogados en el libre ejercicio expertos en derecho bursátil, indicaron que conocen lo que es un instrumento de comercio.

Tabla 2. Instrumento de comercio.

\begin{tabular}{ccc}
\hline ALTERNATIVAS & FRECUENCIA & $\%$ \\
\hline Si & 10 & 100 \\
No & 0 & 0 \\
TOTAL & 10 & 100 \\
\hline
\end{tabular}

\section{Ítems 3. Criterio. Utilizar un título de valor como un instrumento de comercio}

En la Tabla 3, se muestra que de las encuestas realizadas, el $80 \%$ de los abogados en el libre ejercicio expertos en derecho bursátil, creen que sí sería posible utilizar un título de valor como un instrumento de comercio, mientras que el $20 \%$ de los abogados encuestados, indicaron que no.

Tabla 3. Criterio

\begin{tabular}{ccc}
\hline ALTERNATIVAS & FRECUENCIA & $\%$ \\
\hline Si & 8 & 80 \\
No & 2 & 20 \\
TOTAL & 10 & 100 \\
\hline
\end{tabular}




\section{Ítems 4. La Ley de Mercado de Valores otorga un carácter de comercio a los títulos valores}

Se muestra en la Tabla 4, que de los encuestados, el 70\% de los abogados en el libre ejercicio expertos en derecho bursátil, consideran que la Ley de Mercado de Valores otorga un carácter de comercio a los títulos de valores, y el $30 \%$ indica que no es posible.

Tabla 4. Ley de Mercado de Valores.

\begin{tabular}{ccc}
\hline ALTERNATIVAS & FRECUENCIA & $\%$ \\
\hline Si & 7 & 70 \\
No & 3 & 30 \\
TOTAL & $\mathbf{1 0}$ & $\mathbf{1 0 0}$ \\
\hline
\end{tabular}

\section{Ítems 5. Reformar la ley de mercado de valores.}

En la Tabla 5, se muestra que de los encuestados, el $90 \%$ de los abogados en el libre ejercicio expertos en derecho bursátil, estiman que sería importante realizar una reforma en la Ley de Mercado de Valores, para emplear a los títulos valores como instrumentos de comercio, mientras que, solo un $10 \%$ estuvieron en desacuerdo.

Tabla 5. Ley de Mercado de Valores.

\begin{tabular}{ccc}
\hline ALTERNATIVAS & FRECUENCIA & $\%$ \\
\hline Si & 9 & 90 \\
No & 1 & 10 \\
TOTAL & 10 & 100 \\
\hline
\end{tabular}

\section{Ítems 5. Reformar la ley de mercado de valores.}

En la Tabla 5, se muestra que de los encuestados, el $90 \%$ de los abogados en el libre ejercicio expertos en derecho bursátil, estiman que sería importante realizar una reforma en la Ley de Mercado de Valores, para emplear a los títulos valores como instrumentos de comercio, mientras que, solo un $10 \%$ estuvieron en desacuerdo. 
CONCLUSIONES

El mercado de valores es importante para cualquier país porque procura el desarrollo de actividades financieras que fortalecen la economía, aumentando la competencia comercial y promoviendo la creación de instituciones eficientes y fuertes. Esto a su vez traer mayor inversión a las empresas locales por la disponibilidad de financiamiento, y también por la agilidad que implica la realización de estos procesos.

Los títulos de valores son documentos emitidos con varias formalidades, y comercializados en el mercado de valores, por medio de la bolsa y las casas de valores, consecuentemente se puede decir que gozan de veracidad, pues la ley civil garantiza el cumplimiento del derecho económico que representan.

La Superintendencia de Compañías y Valores al ser el mayor órgano de control de las negociaciones de los títulos valor, también necesita de la ayuda conjunta de los demás órganos controladores, como lo son: las casas de valores, bolsa de valores y el mercado de valores, para cerciorarse que todas las emisiones cumplan con las solemnidades que el caso requiere, para su emisión.

El derecho contenido en los títulos valores, representan cifras económicas, cuyo respaldo líquido está a cargo de las empresas o compañías que los emitieron, por lo que deben ser manejados de manera cuidadosa para evitar pérdidas, totales o parciales.

\section{REFERENCIAS}

Andrade, S. (2014). Los títulos valor en el derecho ecuatoriano, Andrade \& Asociados, Quito

Cevallos, V. (2013). Manual de Derecho Mercantil Ecuatoriano. Editorial Jurídica del Ecuador. Quito

Codificación a la Ley de Mercado de Valores, Codificación 2006- 001, Suplemento del Registro Oficial No. 215, 22 de febrero de 2006

Ley del mercado de Valores, Registro Oficial Suplemento 215 de 22 de Febrero del 2006

Ley Orgánica de Fortalecimiento y Optimización del Sector Societario y Bursátil. Registro Oficial, Suplemento $\mathrm{N}^{\circ} 249$, martes 20 de mayo de 2014
Lorenzo, B. (1924). Manual de Derecho Mercantil

Ramírez, C. (2004). Curso de Legislación Mercantil. Loja, Industrial Gráfic Amazonas Cia. Ltda., 2004

Thompson, N. (2006) Guía de intervención bursátil. Segunda Edición, Editorial Jumandi, Quito 